\title{
Manchester Triage System: assessment in an emergency hospital service
}

\author{
Sistema de Triagem de Manchester: avaliação em um serviço hospitalar de emergência \\ Sistema de Triaje Manchester: evaluación en un servicio hospitalario de emergencia
}

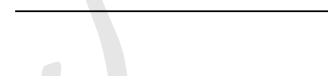 \\ Ana Paula Santos de Jesus' ORCID: 0000-0003-0455-4943 \\ Meiry Fernanda Pinto Okuno" ORCID: 0000-0003-4200-1186 \\ Cassia Regina Vancini Campanharo" ORCID: 0000-0002-7688-2674 \\ Maria Carolina Barbosa Teixeira Lopes" ORCID: 0000-0002-8989-4404 \\ Ruth Ester Assayag Batista" ORCID: 0000-0002-6416-1079}

'Universidade Federal do Recôncavo da Bahia. Santo Antônio de Jesus, Bahia, Brazil. "Universidade Federal de São Paulo. São Paulo, São Paulo, Brazil.

How to cite this article: Jesus APS, Okuno MFP, Campanharo CRV, Lopes MCBT, Batista REA. Manchester Triage System: assessment in an emergency hospital service.

Rev Bras Enferm. 2021;74(3):e20201361. https://doi.org/10.1590/0034-7167-2020-1361

Corresponding author:

Ana Paula Santos de Jesus E-mail: ana_paula@ufrb.edu.br

EDITOR IN CHIEF: Antonio José de Almeida Filho ASSOCIATE EDITOR: Ana Fátima Fernandes

Submission: 01-12-2021

Approval: 03-03-2021

\begin{abstract}
Objectives: to analyze demographic data, clinical profile and outcomes of patients in emergency services according to Manchester Triage System's priority level. Methods: a cross-sectional, analytical study, carried out with 3,624 medical records. For statistical analysis, the Chi-Square Test was used. Results: white individuals were more advanced in age. In the red and white categories, there was a higher percentage of men when compared to women $(p=0.0018)$ and higher prevalence of personal history. Yellow priority patients had higher percentage of pain $(p<0.0001)$. Those in red category had a higher frequency of altered vital signs, external causes, and death outcome. There was a higher percentage of exams performed and hospitalization in the orange category. Blue priority patients had a higher percentage of non-specific complaints and dismissal after risk stratification. Conclusions: a higher percentage of altered vital signs, number of tests performed, hospitalization and death were evidenced in Manchester protocol's high priority categories.

Descriptors: Triage; Emergency Service, Hospital; Emergency Nursing; Outcome and Process Assessment (Health Care); Vital Signs.
\end{abstract}

\section{RESUMO}

Objetivos: analisar os dados demográficos, perfil clínico e desfechos de pacientes em serviço de emergência segundo o nível de prioridade do Sistema de Triagem de Manchester. Métodos: estudo transversal, analítico, realizado com 3.624 prontuários. Para análise estatística, utilizou-se o Teste Qui-Quadrado. Resultados: indivíduos da categoria branca apresentaram idade mais avançada. Nas categorias vermelha e branca, observou-se um maior percentual de homens quando comparados às mulheres $(p=0,0018)$ e maior prevalência de antecedentes pessoais. Pacientes com prioridade amarela apresentaram maior percentual de dor $(p<0,0001)$. Aqueles da categoria vermelha tiveram maior frequência de sinais vitais alterados, causas externas e desfecho óbito. Houve maior percentual de exames realizados e internação na categoria laranja. Pacientes com prioridade azul apresentaram maior percentual de queixas inespecíficas e dispensa após classificação de risco. Conclusões: foi evidenciado maior percentual de sinais vitais alterados, número de exames realizados, internação e óbito nas categorias de alta prioridade do protocolo de Manchester.

Descritores: Triagem; Serviço Hospitalar de Emergência; Enfermagem em Emergência; Avaliação de Processos e Resultados (Cuidados de Saúde); Sinais Vitais.

\section{RESUMEN}

Objetivos: analizar datos demográficos, perfil clínico y evolución de los pacientes en los servicios de urgencias según el nivel de prioridad del Sistema de Triaje Manchester. Métodos: estudio transversal, analítico, realizado con 3.624 historias clínicas. Para el análisis estadístico se utilizó la Prueba de Chi-Cuadrado. Resultados: los individuos de la categoría blanca tenían una edad más avanzada. En las categorías rojo y blanco, hubo un mayor porcentaje de hombres en comparación con las mujeres $(p=0,0018)$ y una mayor prevalencia de antecedentes personales. Los pacientes con prioridad amarilla tenían un mayor porcentaje de dolor $(p<0,0001)$. Aquellos en la categoría roja tenían una mayor frecuencia de signos vitales alterados, causas externas y resultado de muerte. Hubo un mayor porcentaje de exámenes realizados y hospitalización en la categoría naranja. Los pacientes con prioridad azul tuvieron un mayor porcentaje de quejas inespecíficas y despidos después de la clasificación de riesgo. Conclusiones: se encontró un mayor porcentaje de signos vitales alterados, número de pruebas realizadas, hospitalización y muerte en las categorías de alta prioridad del protocolo de Manchester.

Descriptores: Triaje; Servicio de Urgencia en Hospital; Enfermería de Urgencia; Evaluación de Procesos y Resultados (Atención de Salud); Signos Vitales. 


\section{INTRODUCTION}

The need to organize assistance in emergency services (ES) arose from the growing demand from users looking for assistance in this type of service, which makes it the gateway to the health system $^{(1-2)}$. As a consequence, there is an overcrowding of ES, which is a worldwide problem and can lead to an increase in patients' length of stay, time of decision-making by the medical team and performance of diagnostic tests ${ }^{(3)}$, in addition to delay in medication administration in patients with pain ${ }^{(4)}$. Then, there are undesirable outcomes, such as increased costs and mortality ${ }^{(5)}$, which are reflected in the low performance of the health system.

In this context, the use of a triage system, nationally called risk stratification (RS), has great relevance in prioritizing patients with greater severity and in preserving the safety of patients cared for in $\mathrm{ES}^{(6-7)}$. Among the various recognized RS systems, the Manchester Triage System (MTS) ${ }^{(8)}$ has wide international dissemination, being adopted by Brazilian institutions ${ }^{(9-10)}$ and widely used in European countries ${ }^{(11)}$, to direct the best clinical care to patients with greater urgency, to ensure that resources are applied efficiently ${ }^{(11-12)}$ and to reduce the bias of subjectivity involved in the clinical decision-making process of nurses ${ }^{(9)}$.

MTS establishes five categories/clinical priorities, assigned during RS, instituting a color for each of them: red (emergent), orange (very urgent), yellow (urgent), green (not urgent) and blue (not urgent). Each of these categories represents a degree of severity with a respective waiting time for the first medical care ${ }^{(8)}$. In Brazil and Portugal, with the consent of the Brazilian and Portuguese RS groups, the white category is used to designate situations that are not related to a clinical complaint and that arise in $\mathrm{ES}^{(12-13)}$. It is worth mentioning that the inclusion of white color in the MTS is used as a way to identify an organizational dysfunction, i.e., patients who use ES as a gateway for elective or scheduled procedures, returns and referrals for complementary examinations or assessment with specialists, among others ${ }^{(8)}$.

Scientific evidence has already assessed the MTS and measures to assess the quality of this system have been investigated through different concepts, such as reliability and validity in the correct stratification of the most severe patients ${ }^{(9,14-15)}$, effectiveness (assessment of waiting times for care) and the time needed to start treatment ${ }^{(13-14,16)}$ and efficacy (related to the results obtained) ${ }^{(17)}$. Likewise, a national study correlated an institutional RS protocol with clinical aspects and patient outcomes in an $\mathrm{ES}^{(18)}$. However, there is a need for more national studies that can contribute with evidence for the improvement of MTS and nursing decisionmaking in clinical practice in emergency.

The MTS' clinical priority has been used as a quality indicator for assessment in $\mathrm{ES}^{(8,12)}$. Furthermore, the system has been identified as a good predictor of the need for hospitalization, mortality and the use of care resources, becoming an important management tool in addition to $\mathrm{RS}^{(7,15)}$. Therefore, for this study, the hypothesis was established that there is a relationship between the categories/priority assigned by the MTS and age, sex, demographic profile, clinical aspects and the outcome of patients seen in an ES.

\section{OBJECTIVES}

To analyze demographic data, clinical profile and outcomes of patients in emergency services according to Manchester Triage System's priority level.

\section{METHODS}

\section{Ethical aspects}

The study complied with the national regulations for research with human beings and was approved by the Research Ethics Committees of Universidade Federal de São Paulo and Universidade Federal do Recôncavo da Bahia, with the waiver of the Informed Consent Form.

\section{Design and period}

This is an observational, cross-sectional analytical study guided by STROBE, carried out from January to December 2015.

\section{Study site}

The study was carried out at a public general hospital (GH) in the city of Salvador (BA), Brazil, a reference for assistance to medium and high complexity patients. In 2012 the adult and pediatric ES implemented the MTS in RS, aiming to organize the flow of patients who sought care due to spontaneous or regulated demand. RS is performed exclusively by a nurse, who collects data on signs and symptoms, onset of the condition, personal history, medications in use, pain scale, and allergies. Vital signs are checked by a nursing technician, then a nurse assigns the RS color.

\section{Sample, and inclusion and exclusion criteria}

The study population consisted of the medical records of patients seen in the adult ES. For the sample calculation, a pilot study was carried out, which used records of patients treated at the GH's adult ES, in December 2014, using a simple random sampling technique without replacement, with 95\% confidence and a maximum permissible error of $2 \%$, with a minimum sample of 2,160 patients estimated. Aiming at increasing reliability and considering that the filed medical records were organized by day, month and year, a systematic sampling was chosen to select the participants, in which the first medical record in the box was defined as a random starting point; then, one out of every six members of the population was manually selected to compose the sample, totaling 4,157 medical records.

The study included 3,624 records of patients submitted to RS from January 1 to December 31, 2015. Thus, 533 records were excluded after selecting participants, because the RS attendance records were incomplete, without the RS color registration.

\section{Study protocol}

The data were accessed manually at the Medical and Statistical Archiving Service of the institution, from September 2015 to February to 2016, using the instrument built by the researchers to 
survey the variables contained in patients' medical records. The variables studied were: age, sex, personal history, complaint, RS categories of the MTS, blood pressure (BP), heart rate (HR), respiratory rate (RR), body temperature, oxygen saturation measured by pulse oximetry $\left(\mathrm{SpO}_{2}\right)$, capillary blood glucose, presence or absence of pain, diagnostic tests performed in ES. The outcomes were discharged from hospital, discharge from patients after RS, hospitalization, transfer and death.

The main complaint was categorized according to the organic systems in neurological, respiratory, digestive, cardiological, genitourinary, vascular, endocrine, skin and attachments, mental, ophthalmological, otorhinolaryngological, dental and immunological. Complaints that could not be associated with a specific organic system were stratified as nonspecific, such as pain, external causes (trauma, falling and burning), intoxication (poisoning and accidents with venomous animals), anorexia/inappetence, fainting/vertigo, edema, general malaise, among others.

The data referring to RS categories followed the MTS determinations, according to clinical priority (red - immediate service; orange - 10 minutes; yellow - 60 minutes; green - 120 minutes; blue - 240 minutes $)^{(8)}$, corresponding to high priority: red and orange, and low priority: yellow, green, blue, in addition to the white category.

Vital sign parameters were stratified as normal or altered: normal BP (systolic blood pressure (SBP) $\leq 120 \mathrm{mmHg}$ and diastolic blood pressure (DBP) $\leq 80 \mathrm{mmHg}$ ); altered $\mathrm{BP}$ (prehypertension: SBP at 121 to $139 \mathrm{mmHg}$ and/or DBP at 80 to $89 \mathrm{mmHg}$; isolated hypertension (HP): SBP $\geq 140 \mathrm{mmHg}$ and DBP $<90 \mathrm{mmHg}$; HP stage 1: SBP at 140 to $159 \mathrm{mmHg}$ and/or DBP at 90 to $99 \mathrm{mmHg}$; HP stage 2: SBP in 160 to $179 \mathrm{mmHg}$ and/or DBP in 100 to 109 $\mathrm{mmHg}$; HP stage 3: SBP $\geq 180 \mathrm{mmHg}$ and/or DBP $\geq 110 \mathrm{mmHg}$ ) ${ }^{(19)}$; hypotension (SBP $<90 \mathrm{mmHg}$ or mean arterial pressure (MAP) $<65 \mathrm{mmHg}$ ) ${ }^{(20)}$; normal HR at 50-100 bpm; altered HR (tachycardia> 100 bpm, bradycardia <50 bpm and cardiac arrest) ${ }^{(21)}$; normal RR (12 to $22 \mathrm{rpm}$ ); altered RR (tachypnea $>22 \mathrm{rpm}$, bradypnea $<12$ rpm and apnea or gasping); normal temperature $\left(35-37.4^{\circ} \mathrm{C}\right)$; altered temperature (feverish, 37.5 to $38.4^{\circ} \mathrm{C}$; hot, 38.5 to $40.9^{\circ} \mathrm{C}$; very hot, $\geq 41^{\circ} \mathrm{C}$ and hypothermia $<35^{\circ} \mathrm{C}$ ); normal $\mathrm{SpO}_{2}(\geq 95 \%)$; altered $\mathrm{SpO}_{2}$ (low $<95 \%$ in room air and very low $<95 \%$ with oxygen or $<90 \%$ in room air ${ }^{(8)}$; normal capillary blood glucose ( $<180 \mathrm{mg} / \mathrm{dL}$ if postprandial or 70 to $130 \mathrm{mg} / \mathrm{dL}$ if fasting in diabetes mellitus (DM) and 80 to $126 \mathrm{mg} / \mathrm{dL}$ if postprandial) or 65 to $100 \mathrm{mg} / \mathrm{dL}$ if fasting in non-DM; altered blood glucose ( $\geq 180$ $\mathrm{mg} / \mathrm{dL}$ if postprandial and $\geq 130 \mathrm{mg} / \mathrm{dL}$ if fasting in $\mathrm{DM}) ;(\geq 126$ $\mathrm{mg} / \mathrm{dL}$ if postprandial and $\geq 100 \mathrm{mg} / \mathrm{dL}$ if fasting in non-DM); hypoglycemia $(<70 \mathrm{mg} / \mathrm{dL})^{(22)}$.

\section{Analysis of results, and statistics}

The program Statistical Package for Social Science, version 23, was used for processing and statistical analysis. For descriptive analysis of age, mean, standard deviation, median, minimum and maximum were calculated. For categorical variables, frequency and percentage were calculated. To associate RS categories with age, analysis of variance (ANOVA) was used; to RS categories with sex, vital signs, diagnostic tests, personal history and outcomes, the chi-square test was used and, when necessary, the likelihood ratio test. The level of significance considered was $5 \%$ ( $p$ value $<0.05$ ).

\section{RESULTS}

The mean age was $48.8 \pm 18.8$ years and most were women (51.8\%). When relating RS categories with age, individuals stratified as white were older, and patients in the green category were younger when compared to the others ( $p<0.0001)$. There was a difference between RS categories and sex $(p=0.0018)$. In the red and white category, a higher percentage of men was observed (Table 1).

The most prevalent history was HP (24.8\%), DM (11.4\%) and cerebrovascular disease (CVD; 7.1\%). The results of the association of RS categories and personal history are shown in Table 1. Patients stratified as white had a higher percentage of HP, CVD and ulcerative disease, when compared with the other categories ( $p$ $<0.0001$ ). Those in the red category had a higher percentage of DM, heart disease and dyslipidemia, and those with red, orange and yellow priority, had a higher percentage of neoplasms, when compared with the others $(p=0.0015)$.

There was a significant difference between RS categories and the measured vital signs ( $p<0.0001)$. Patients stratified in the red category had a higher percentage of changes in $\mathrm{BP}, \mathrm{HR}, \mathrm{RR}, \mathrm{SpO}_{2^{\prime}}$ when compared with the others. The high prevalence $(82.6 \%)$ of altered BP was also noted in all RS categories. Those stratified in the orange categories have a higher percentage of altered $\mathrm{SpO}_{2}$ than the yellow, green and blue categories. There was no difference in relation to temperature $(p=0.0691)$. Patients stratified as yellow priority had a higher percentage of pain records $(p<0.0001)$. All patients stratified in the red category had altered blood glucose (Table 2).

In the analysis of altered vital signs, patients in the red category had a higher percentage of hypotension, cardiorespiratory arrest, bradycardia, bradypsy, hypothermia and very low $\mathrm{SpO}_{2}$. It was found that all patients with hypoglycemia were stratified in the red category. Those in the white category recorded a higher percentage of isolated hypertension and stage 3 hypertension. In the orange category, there was a higher percentage of stage 2 hypertension, tachycardia and tachypnea. Those in the yellow category had a higher frequency of stage 1 hypertension. Patients in the green and blue categories had a higher frequency of prehypertension and normal vital signs. With regard to temperature, patients with orange priority had a higher percentage of "hot adults"; those in the yellow category, the highest percentage of "febrile" patients; the "very hot" were stratified in the yellow and green categories.

When comparing RS categories with the most prevalent complaints, white patients had a higher percentage of neurological and digestive complaints than other categories; those in the orange categories had a higher percentage of digestive complaints than other patients; those with green and blue priority had a higher percentage of non-specific complaints than other categories. With regard to nonspecific complaints, patients with red priority had a higher percentage of external causes, and those with blue risk, a higher percentage of general malaise than other patients (Table 3 ).

In the association of RS categories with diagnostic examinations, it was found that patients in the white category had a higher percentage of examinations performed. Those with orange priority had a higher percentage of examinations, when compared to red, 
yellow, green and blue priorities. Those stratified as white had a higher percentage of undergoing an examination and a higher prevalence for cranial computed tomography (CT) and upper digestive endoscopy. Those in the orange category, on the other hand, had a higher percentage of performing two or more tests, with a higher frequency of electrocardiogram (ECG), laboratory tests and ultrasounds. Patients in the red category had a higher percentage of X-rays than other patients (Table 4).
As for the outcome after care at the ES. patients with red priority had a higher percentage of death, and those in the orange and yellow categories had higher percentages of hospital discharge. There was a higher percentage of hospitalization in the orange category. Those with green and blue priority had a higher frequency of dismissal after RS; and those in the white category, higher percentage of transfer, when compared with the other categories $(p<0.0001)$ (Table 5).

Table 1 - Distribution of Manchester Triage System categories according to demographic variables and personal history, Salvador, Bahia, Brazil, 2015

\begin{tabular}{|c|c|c|c|c|c|c|c|c|}
\hline & \multirow[b]{2}{*}{$\begin{array}{c}\text { Red } \\
n=143\end{array}$} & \multicolumn{4}{|c|}{ Manchester Triage System Categories n (\%) } & \multicolumn{3}{|c|}{ Total n (\%) } \\
\hline & & $\begin{array}{l}\text { Orange } \\
n=769\end{array}$ & $\begin{array}{c}\text { Yellow } \\
n=1142\end{array}$ & $\begin{array}{c}\text { Green } \\
n=1004\end{array}$ & $\begin{array}{c}\text { Blue } \\
\mathbf{n}=\mathbf{2 9 8}\end{array}$ & $\begin{array}{l}\text { White } \\
n=268\end{array}$ & $N=3624$ & $p$ value \\
\hline Age & & & & & & & & $<0.0001^{*}$ \\
\hline Mean $(S D)^{+}$ & $51.8(18.8)$ & $48.7(19.0)$ & $48.8(18.7)$ & $46.5(18.1)$ & $47.4(18.6)$ & $58.2(18.9)$ & $48.8(18.8)$ & \\
\hline Median & 54 & 47 & 47 & 45 & 46 & 59.5 & 47 & \\
\hline Min - Max & $18-90$ & $18-99$ & 18-105 & $18-101$ & $18-99$ & $18-114$ & $18-114$ & \\
\hline Sex & & & & & & & & $0.0018^{\ddagger}$ \\
\hline Male & $90(63.4)$ & $376(48.9)$ & $538(47.1)$ & $457(45.5)$ & $144(48.3)$ & $142(53)$ & $1747(48.2)$ & \\
\hline Female & $52(36.6)$ & $393(51.1)$ & 604 (52.9) & $547(54.5)$ & $154(51.7)$ & $126(47)$ & $1876(51.8)$ & \\
\hline \multicolumn{9}{|l|}{ Personal history } \\
\hline Hypertension & $43(30.1)$ & $225(29.3)$ & $313(27.4)$ & $164(16.3)$ & $49(16.4)$ & 105 (39.2) & 899 (24.8) & $<0.0001^{\ddagger}$ \\
\hline Diabetes & 37 (25.9) & $91(11.8)$ & 131 (11.) & $72(7)$ & 37 (12.4) & $46(17.2)$ & $414(11.4)$ & $<0.0001^{\ddagger}$ \\
\hline$C V D^{\S}$ & $15(10.5)$ & $78(10.1)$ & $58(5.1)$ & $15(1.5)$ & $5(1.7)$ & $87(32.5)$ & $258(7.1)$ & $<0.0001^{\ddagger}$ \\
\hline Heart diseases & $18(12.6)$ & $52(6.8)$ & $26(2.3)$ & $14(1.4)$ & $4(1.3)$ & $12(4.5)$ & $126(3.5)$ & $<0.0001^{\ddagger}$ \\
\hline Surgeries & $6(4.2)$ & $48(6.2)$ & $65(5.7)$ & $20(2)$ & $7(2.3)$ & $12(4.5)$ & $158(4.4)$ & $<0.0001^{\ddagger}$ \\
\hline Alcohol use & $6(4.2)$ & $48(6.2)$ & $65(5.7)$ & $20(2)$ & $7(2.3)$ & $12(4.5)$ & $158(4.4)$ & $<0.0001^{\ddagger}$ \\
\hline Smoking & $4(2.8)$ & $30(3.9)$ & $37(3.2)$ & $15(1.5)$ & $6(2)$ & $6(2.2)$ & $98(2.7)$ & $0.0378^{\ddagger}$ \\
\hline Kidney disease & $7(4.9)$ & $22(2.9)$ & $31(2.7)$ & $17(1.7)$ & $2(0.7)$ & $6(2.2)$ & $85(2.3)$ & $0.0484^{\ddagger}$ \\
\hline PVD\| & $3(2.1)$ & $21(2.7)$ & $36(3.2)$ & $22(2.2)$ & $1(0.3)$ & $7(2.6)$ & $90(2.5)$ & $0.1335^{\ddagger}$ \\
\hline Neoplasms & $5(3.5)$ & $16(2.1)$ & $29(2.5)$ & $4(0.4)$ & $3(1)$ & $4(1.5)$ & $61(1.7)$ & $0.0015^{\ddagger}$ \\
\hline Liver disease & $4(2.8)$ & $20(2.6)$ & $22(1.9)$ & $4(0.4)$ & $3(1)$ & $4(1.5)$ & $57(1.6)$ & $0.0043^{\ddagger}$ \\
\hline Alzheimer's disease & $4(2.8)$ & $8(1)$ & $8(0.7)$ & $3(0.3)$ & $1(0.3)$ & $6(2.2)$ & $30(0.8)$ & $0.0108^{\Uparrow}$ \\
\hline Ulcer disease & $3(2.1)$ & $26(3.4)$ & $5(0.4)$ & $0(0)$ & $1(0.3)$ & $15(5.6)$ & $50(1.4)$ & $<0.0001^{\ddagger}$ \\
\hline COPD $^{* *} /$ asthma & $1(0.7)$ & $7(0.9)$ & $5(0.4)$ & $5(0.5)$ & $2(0.7)$ & $0(0)$ & $20(0.6)$ & $0.4232^{\pi}$ \\
\hline AIDS & $0(0)$ & $4(0.5)$ & $9(0.8)$ & $3(0.3)$ & $0(0)$ & $2(0.7)$ & $18(0.5)$ & $0.2003^{\natural}$ \\
\hline Dyslipidemia & $4(2.8)$ & $6(0.8)$ & $1(0.1)$ & $3(0.3)$ & $0(0)$ & $0(0)$ & $14(0.4)$ & $0.0013^{\Uparrow}$ \\
\hline Others & $10(7)$ & $71(9.2)$ & $75(6.6)$ & $40(4)$ & $11(3.7)$ & $23(8.6)$ & $230(6.3)$ & $<0.0001^{\ddagger}$ \\
\hline
\end{tabular}

Note: *Analysis of variance ${ }^{\dagger}$ Standard deviation; ${ }^{*}$ chi-square test; $\S C V D$-cerebrovascular disease; $\| P V D$ - peripheral vascular disease; $\uparrow$ likelihood ratio test; ${ }^{* *}$ COPD - chronic obstructive pulmonary disease.

Table 2 - Distribution of Manchester Triage System categories according to vital signs, Salvador, Bahia, Brazil, 2015

\begin{tabular}{|c|c|c|c|c|c|c|c|c|}
\hline \multicolumn{9}{|c|}{ Manchester Triage System Categories n (\%) } \\
\hline & $\begin{array}{c}\text { Red } \\
n=143\end{array}$ & $\begin{array}{c}\text { Orange } \\
n=769\end{array}$ & $\begin{array}{c}\text { Yellow } \\
n=1142\end{array}$ & $\begin{array}{c}\text { Green } \\
n=1004\end{array}$ & $\begin{array}{c}\text { Blue } \\
n=298\end{array}$ & $\begin{array}{l}\text { White } \\
n=268\end{array}$ & Total n (\%) & $p$ value \\
\hline Vital Signs & & & & & & & & $<0.0001^{\dagger}$ \\
\hline Yes & $128(89.5)$ & $717(93.2)$ & $1033(90.5)$ & $856(85.3)$ & $236(79.2)$ & $251(93.7)$ & $3221(88.9)$ & \\
\hline No & $15(10.5)$ & $52(6.8)$ & $109(9.5)$ & $148(14.7)$ & $62(20.8)$ & $17(6.3)$ & $403(11.1)$ & \\
\hline \multicolumn{9}{|l|}{$\mathrm{BP}$} \\
\hline Normal & $13(10.7)$ & 109 (15.6) & $164(16.3)$ & $160(19.2)$ & $46(19.9)$ & $54(22.1)$ & $546(17.4)$ & $0.0247^{\dagger}$ \\
\hline Altered & $109(89.3)$ & $589(84.4)$ & $842(83.7)$ & $675(80.8)$ & $185(80.1)$ & $190(77.9)$ & $2590(82.6)$ & \\
\hline \multicolumn{9}{|l|}{$\mathrm{HR}$} \\
\hline Normal & $39(33.6)$ & $493(74.2)$ & $748(76.8)$ & $625(79.1)$ & $184(83.3)$ & $192(80)$ & $2281(75.9)$ & $<0.0001^{\dagger}$ \\
\hline Altered & $77(66.4)$ & $171(25.8)$ & $226(23.2)$ & 165 (20.9) & $37(16.7)$ & $48(20)$ & $724(24.1)$ & \\
\hline \multicolumn{9}{|l|}{$\mathrm{RR}$} \\
\hline Normal & $12(17.4)$ & $24(80)$ & $47(90.4)$ & $54(93.1)$ & $12(92.3)$ & $15(83.3)$ & $164(68.3)$ & $<0.0001^{\dagger}$ \\
\hline Altered & $57(82.6)$ & $6(20)$ & $5(9.6)$ & $4(6.9)$ & $1(7.7)$ & $3(16.7)$ & $76(31.7)$ & \\
\hline \multicolumn{9}{|l|}{$\mathrm{T}$} \\
\hline Normal & $13(76.5)$ & $182(89.2)$ & $233(81.8)$ & $254(87.3)$ & $70(92.1)$ & $61(87.1)$ & $813(86.2)$ & $0.0691^{\dagger}$ \\
\hline Altered & $4(23.5)$ & $22(10.8)$ & $52(18.2)$ & $37(12.7)$ & $6(7.9)$ & $9(12.9)$ & $130(13.8)$ & \\
\hline \multicolumn{9}{|l|}{$\mathrm{SpO}_{2}$} \\
\hline Normal & $38(36.5)$ & $533(92.9)$ & 741 (96.1) & $676(98.3)$ & $121(99.2)$ & $208(91.2)$ & $2317(93.2)$ & $<0.0001^{\dagger}$ \\
\hline Altered & $66(63.5)$ & $41(7.1)$ & $30(3.9)$ & $12(1.7)$ & $1(0.8)$ & $20(8.8)$ & $170(6.8)$ & \\
\hline \multicolumn{9}{|c|}{ Blood glucose } \\
\hline Normal & $0(0)$ & $24(10.4)$ & $40(15)$ & $13(7.6)$ & $7(15.2)$ & $15(17.2)$ & 99 (11.7) & $0.0086^{\dagger}$ \\
\hline Altered & $48(100)$ & 206 (89.6) & $226(85)$ & $157(92.4)$ & $39(84.8)$ & $72(82.8)$ & $748(88.3)$ & \\
\hline
\end{tabular}




\begin{tabular}{|c|c|c|c|c|c|c|c|c|}
\hline \multicolumn{9}{|c|}{ Manchester Triage System Categories n (\%) } \\
\hline & $\begin{array}{c}\text { Red } \\
n=143\end{array}$ & $\begin{array}{l}\text { Orange } \\
n=769\end{array}$ & $\begin{array}{c}\text { Yellow } \\
n=1142\end{array}$ & $\begin{array}{c}\text { Green } \\
n=1004\end{array}$ & $\begin{array}{c}\text { Blue } \\
n=298\end{array}$ & $\begin{array}{l}\text { White } \\
n=268\end{array}$ & Total n (\%) & $p$ value \\
\hline \multicolumn{9}{|l|}{ Pain } \\
\hline Yes & $20(14)$ & $490(63.7)$ & $861(75.4)$ & $671(66.8)$ & $169(56.7)$ & $53(19.8)$ & $2264(62.5)$ & $<0.0001^{\ddagger}$ \\
\hline No & $123(86)$ & $279(36.3)$ & $281(24.6)$ & $333(33.2)$ & $129(43.3)$ & $215(80.2)$ & $1360(37.5)$ & \\
\hline
\end{tabular}

Note: *At least one vital sign measured; ${ }^{+}$chi-square test; ${ }^{*}$ likelihood ratio test.

Table 3 - Distribution of Manchester Triage System categories according to complaints, Salvador, Bahia, Brazil, 2015

\begin{tabular}{|c|c|c|c|c|c|c|c|c|}
\hline \multicolumn{9}{|c|}{ Manchester Triage System Categories n (\%) } \\
\hline & $\begin{array}{c}\text { Red } \\
n=143\end{array}$ & $\begin{array}{l}\text { Orange } \\
n=769\end{array}$ & $\begin{array}{c}\text { Yellow } \\
n=1142\end{array}$ & $\begin{array}{c}\text { Green } \\
n=1004\end{array}$ & $\begin{array}{c}\text { Blue } \\
n=298\end{array}$ & $\begin{array}{l}\text { White } \\
n=268\end{array}$ & Total n (\%) & $p$ value \\
\hline Main complaint & & & & & & & & $<0.0000^{*}$ \\
\hline Nonspecific & $45(31.5)$ & $345(44.9)$ & $664(58.1)$ & $618(61.6)$ & $198(66.4)$ & $34(12.7)$ & $1904(52.5)$ & \\
\hline Neurological & $18(12.6)$ & 153 (19.9) & $128(11.2)$ & $20(2)$ & $6(2)$ & $162(60.4)$ & $487(13.4)$ & \\
\hline Skin and attachment & $2(1.4)$ & $33(4.3)$ & $106(9.3)$ & $149(14.8)$ & $38(12.8)$ & $3(1.1)$ & $331(9.1)$ & \\
\hline Digestive & $8(5.6)$ & $128(16.6)$ & $68(6)$ & $49(4.9)$ & $12(4)$ & $42(15.7)$ & $307(8.5)$ & \\
\hline Respiratory & $10(7)$ & $32(4.2)$ & $38(3.3)$ & $34(3.4)$ & $13(4.4)$ & $1(0.4)$ & $128(3.5)$ & \\
\hline Cardiac & $32(22.4)$ & $16(2.1)$ & $8(0.7)$ & $14(1.4)$ & $5(1.7)$ & $2(0.7)$ & $77(2.1)$ & \\
\hline Nonspecific complaints & & & & & & & & $<0.0000^{*}$ \\
\hline Pain & $4(8.9)$ & $207(60)$ & $461(69.4)$ & $417(67.5)$ & $133(67.2)$ & $14(41.2)$ & $1236(64.9)$ & \\
\hline External causes & $34(75.6)$ & $77(22.3)$ & $124(18.7)$ & $92(14.9)$ & $16(8.1)$ & $11(32.4)$ & $354(18.6)$ & \\
\hline Intoxication & $4(8.9)$ & $33(9.6)$ & $35(5.3)$ & $33(5.3)$ & $4(2)$ & $1(2.9)$ & $110(5.8)$ & \\
\hline Anorexia/inappetence & $0(0)$ & $2(0.6)$ & $1(0.2)$ & $3(0.5)$ & $2(1)$ & $0(0)$ & $8(0.4)$ & \\
\hline Faint & $2(4.4)$ & $15(4.3)$ & $9(1.4)$ & $5(0.8)$ & $3(1.5)$ & $1(2.9)$ & $35(1.8)$ & \\
\hline Swelling & $0(0)$ & $1(0.3)$ & $9(1.4)$ & $26(4.2)$ & $6(3)$ & $0(0)$ & $42(2.2)$ & \\
\hline General malaise & $1(2.2)$ & $9(2.6)$ & $16(2.4)$ & $33(5.3)$ & $18(9.1)$ & $1(2.9)$ & $78(4.1)$ & \\
\hline Others & $0(0)$ & $1(0.3)$ & $9(1.4)$ & $9(1.5)$ & $16(8.1)$ & $6(17.6)$ & $41(2.2)$ & \\
\hline
\end{tabular}

Note: ${ }^{*}$ chi-square test.

Table 4 - Distribution of Manchester Triage System Categories according to diagnostic tests, Salvador, Bahia, Brazil, 2015

\begin{tabular}{|c|c|c|c|c|c|c|c|c|}
\hline & \multirow[b]{2}{*}{$\begin{array}{c}\text { Red } \\
n=143\end{array}$} & \multicolumn{4}{|c|}{ Manchester Triage System Categories n (\%) } & \multicolumn{3}{|c|}{ Total n (\%) } \\
\hline & & $\begin{array}{l}\text { Orange } \\
n=769\end{array}$ & $\begin{array}{c}\text { Yellow } \\
n=1142\end{array}$ & $\begin{array}{c}\text { Green } \\
n=1004\end{array}$ & $\begin{array}{c}\text { Blue } \\
n=298\end{array}$ & $\begin{array}{l}\text { White } \\
n=268\end{array}$ & $N=3624$ & $p$ value \\
\hline \multicolumn{9}{|l|}{ Examination } \\
\hline Yes & $60(42)$ & $508(66.1)$ & $422(37)$ & $108(10.8)$ & $23(7.7)$ & $214(79.9)$ & $1335(36.8)$ & $<0.0001^{*}$ \\
\hline No & $83(58)$ & $261(33.9)$ & $720(63)$ & $896(89.2)$ & $275(92.3)$ & $54(20.1)$ & $2289(63.2)$ & \\
\hline \multicolumn{9}{|c|}{ Number of examinations } \\
\hline 1 & $31(21.7)$ & $299(38.9)$ & $312(27.3)$ & $93(9.3)$ & $18(6)$ & $189(70.5)$ & $942(26)$ & $<0.0001^{*}$ \\
\hline 2 or more & $29(20.3)$ & $209(27.2)$ & $110(9.6)$ & $15(1.5)$ & $5(1.7)$ & $25(9.3)$ & $393(10.8)$ & \\
\hline \multicolumn{9}{|l|}{ Types of laboratory } \\
\hline tests & $36(25.2)$ & $254(33)$ & $178(15.6)$ & $46(4.6)$ & $10(3.4)$ & $23(8.6)$ & $547(15.1)$ & $<0.0001^{*}$ \\
\hline $\mathrm{CT}^{\dagger}$ & $20(14)$ & $185(24.1)$ & $153(13.4)$ & $20(2)$ & $4(1.3)$ & $153(57.1)$ & $535(14.8)$ & $<0.0001^{*}$ \\
\hline X-ray & $24(16.8)$ & $101(13.1)$ & $73(6.4)$ & $17(1.7)$ & $7(2.3)$ & $9(3.4)$ & $231(6.4)$ & $<0.0001^{*}$ \\
\hline Electrocardiogram & $16(11.2)$ & $101(13.1)$ & $38(3.3)$ & $12(1.2)$ & $0(0)$ & $7(2.6)$ & $174(4.8)$ & $<0.0001^{*}$ \\
\hline Endoscopy & $0(0)$ & $62(8.1)$ & $41(3.6)$ & $15(1.5)$ & $3(1)$ & $33(12.3)$ & $154(4.2)$ & $<0.0001^{*}$ \\
\hline Ultrasound & $4(2.8)$ & $53(6.9)$ & $48(4.2)$ & $11(1.1)$ & $5(1.7)$ & $8(3)$ & $129(3.6)$ & $<0.0001^{*}$ \\
\hline Others & $11(7.7)$ & $35(4.6)$ & $27(2.4)$ & $7(0.7)$ & $1(0.3)$ & $16(6)$ & $97(2.7)$ & $<0.0001^{*}$ \\
\hline
\end{tabular}

Note: ${ }^{*}$ chi-square test; ${ }^{+} \mathrm{CT}$ - cranial computed tomography.

Table 5 - Distribution of the Manchester Triage System categories according to patient outcomes, Salvador, Bahia, Brazil, 2015

\begin{tabular}{|c|c|c|c|c|c|c|c|c|}
\hline \multicolumn{9}{|c|}{ Manchester Triage System Categories n (\%) } \\
\hline & Red & Orange & Yellow & Green & Blue & White & Total n (\%) & $p$ value \\
\hline Outcomes & & & & & & & & $<0.0001 *$ \\
\hline Discharge & $61(42.7)$ & $629(81.8)$ & $662(58)$ & $252(25.1)$ & $38(12.8)$ & $75(28)$ & $1717(47.4)$ & \\
\hline Dismissal & $0(0)$ & $34(4.4)$ & $420(36.8)$ & 740 (73.7) & $252(84.6)$ & $8(3)$ & $1454(40.1)$ & \\
\hline Hospitalization & $5(3.5)$ & $49(6.4)$ & $18(1.6)$ & $2(0.2)$ & $0(0)$ & $9(3.4)$ & $83(2.3)$ & \\
\hline Transfer & $6(4.2)$ & $40(5.2)$ & $39(3.4)$ & $10(1)$ & $8(2.7)$ & $172(64.2)$ & $275(7.6)$ & \\
\hline Death & 71 (49.6) & $17(2.2)$ & $3(0.3)$ & $0(0)$ & $0(0)$ & $4(1.5)$ & $95(2.6)$ & \\
\hline
\end{tabular}

Note: * chi-square test.

\section{DISCUSSION}

In this study, men were stratified in a higher percentage in the white and red category, which may be associated with late search for medical care ${ }^{(23)}$, in addition to the higher prevalence of patients with the occurrence of external causes in the red category, which aggravates their clinical risk. It is important to highlight the scarcity of publications that associate the priority 
levels of MTS with sociodemographic data. Some studies ${ }^{(10,18,24-25)}$ described the prevalence of sex and the average age of the population studied and another ${ }^{(26)}$ associated the complaint of pain in RS with sex and age.

Regarding comorbidities, the highest prevalence was HP and $\mathrm{DM}$, confirming findings from other studies ${ }^{(18,26)}$. The presence of a personal history was significantly associated with RS categories. Patients with red and orange priority had a higher prevalence of DM and heart disease, when compared to the yellow, green and blue categories. HP and CVD were more prevalent in the white category. It is noteworthy that $\mathrm{HP}$, along with $\mathrm{DM}$, has been responsible for the high frequency of hospitalizations ${ }^{(19)}$, possibly for its complications and being considered risk factors for other diseases, such as stroke, coronary and kidney diseases, which can justify the increase in demand in the $\mathrm{ES}^{(26)}$.

The highest prevalence of neoplasms in the red, orange and yellow category stands out, which can be attributed to the increasing number of cancer patients in the general population, the severity of the disease and the reactions caused by their treatments, leading patients to seek care in the ES. Evidence points out that, although cancer patients represent only a small percentage of admissions in the ES, most were stratified as high priority and have high rates of admission and mortality ${ }^{(27)}$, corroborating the findings found in this study.

Regarding the association of RS categories and vital signs, it was observed that in all MTS categories there was a higher prevalence of registration of at least one vital sign. However, it is noteworthy that the completeness of vital signs is necessary to increase patient safety, identify and prevent adverse events, in addition to improving the flow of clinical care ${ }^{(28-29)}$.

Recent evidence confirms that vital signs are critical markers of disease severity in the $\mathrm{ES}^{(30-31)}$. Early warning scores, such as the Modified Early Warning Score (MEWS) and the National Early Warning Score (NEWS), which use the variables vital signs and the measure of the level of consciousness, are useful in stratifying risks, predicting the clinical outcome ${ }^{(24,32)}$ and restratification of patients seen in the $\mathrm{ES}^{(33)}$. However, it is clear that some MTS flowcharts and discriminators are unclear as to the need to measure vital signs, with reference to the definition established for each discriminator ${ }^{(17)}$. Moreover, the MTS recommends that time-consuming assessments, such as temperature and pulse measurement, should not be performed if these values are not necessary for setting priorities ${ }^{(8)}$.

Little research has investigated the association between vital signs assessed on arrival at ES and priority levels of MTS in adults. A study carried out in Portugal found a significant association between the high priority groups of the MTS (red and orange). Changing HR to more or less physiological patterns led to an increase in clinical priority. Among the patients who measured $\mathrm{BP}$, the normotensive individuals were mostly stratified as a lower priority, while those with hypotension and severe hypertension were stratified as a high priority. Regarding RR and capillary glycemia, there was also a significant difference between the groups: among the patients who had altered RR, $80 \%$ were stratified as red and orange and none in the blue category. All patients with hypoglycemia were stratified as red priority ${ }^{(10)}$, which is similar to the results of this study.
In this study, in relation to temperature, there was no significant difference between RS categories, which can be justified by the lack of registration of this vital data. Patients with a temperature $\geq$ $41^{\circ} \mathrm{C}$ were stratified in the yellow and green categories, without it being a high priority indicator. It is noteworthy that temperature is used as a general discriminator in the MTS, establishing the stratification orange for hypothermic and very hot adult, yellow for hot patient and green for feverish adult ${ }^{(8)}$.

The lack of registration of RR and temperature was significant in this study. In RS, the assessment of these data, associated with $H R$, may favor the recognition and early treatment of serious conditions, such as sepsis ${ }^{(34)}$. Recently, the MTS, for the purpose of early identification of suspected sepsis, introduced the discriminator "possible sepsis" in some of its flowcharts. The presence of two of the criteria of the systemic inflammatory response syndrome (temperature $>38^{\circ} \mathrm{C}$ or $<36^{\circ} \mathrm{C}, \mathrm{RR}>20 \mathrm{rpm}$ or partial pressure of carbon dioxide in arterial blood $<32 \mathrm{mmHg}, \mathrm{HR}>90 \mathrm{bpm}$, among others) can lead patients to be stratified in very urgent and, eventually, in urgent priority, or even in non-urgent priority. Patients with organ dysfunction are usually stratified as orange or red priority, and this determines the early opening of the sepsis protocol after $\operatorname{RS}^{(12,20)}$.

Pain assessment as a vital sign helps nurses to classify patients in RS priority categories, and the intensity of pain influences stratification of greater severity ${ }^{(8)}$. In this study, the highest percentages of patients with pain records were in the yellow category, which is similar to the findings of a study conducted in the ES of Sergipe, Brazil ${ }^{(25)}$. It is important to note that acute pain can cause changes in BP, HR and decreased supply of oxygen to tissues, which requires effective strategies from professionals for their relief and satisfaction of users who seek health services ${ }^{(25)}$.

In an analysis of MTS categories according to complaints, patients stratified in the white category had a higher percentage of neurological and digestive complaints. This finding is justified, since the ES studied is a reference center for high complexity care for individuals with stroke and digestive hemorrhage; often, patients are admitted or referred for assessment of neurology and gastro-hepatology specialties.

The presence of nonspecific complaints was significantly associated with low priority categories. Pain is the most common symptom reported by patients seeking care in the $\mathrm{ES}^{(18,25-26)}$, similar to that found in this investigation. External causes were significantly associated with the red priority, when compared to other non-specific complaints. This finding, in part, corroborates the study carried out in an ES in São Paulo that found a higher percentage of trauma in the red category ${ }^{(18)}$.

For most patients, diagnostic tests were not required, which may be associated with the prevalence of patients with low clinical complexity seen at the service. Laboratory tests are among the most used resources to support clinical practice in the $\mathrm{ES}^{(18,35-36)}$, a result that corroborates this study. The growing demand for examinations can contribute to the overcrowding of the $\operatorname{ES}^{(3,18)}$, as the waiting time for the result increases patients' permanence in this service ${ }^{(18)}$. A study shows that the use of CT and laboratory tests also increases doctors' decision-making time ${ }^{(3)}$.

In an analysis of RS categories, according to the diagnostic examination, it was found that the higher the severity category, the greater the number of examinations, a result consistent with 
that of another study ${ }^{(18)}$. ECG and laboratory tests were the most performed in patients with orange and red priorities, which can be attributed to the recommendation of the MTS so that all patients admitted with complaints of precordial pain are referred directly to ECG in order to reduce the time taken to identify acute coronary syndrome with ST segment elevation ${ }^{(8)}$.

In this study, a statistically significant result was observed between the clinical outcome and RS categories $(p<000.1)$. Patients in the red category had a higher percentage of deaths. Research that correlated RS categories with the outcomes of care also found a higher occurrence of deaths in high-priority patients ${ }^{(7,18,37)}$. Another study ${ }^{(17)}$ also found that MTS is a good predictor of death, i.e., the greater the severity of patients, the greater the chance of dying.

Another aspect to be highlighted refers to the outcome dismissal of patients without medical care after RS. RS nurses assessed, stratified and directed patients to seek another health service, with the highest percentage of patients with low urgent priority (blue) followed by non-urgent priority (green). This data becomes relevant, since it contradicts the recommendations of the Ministry of Health ${ }^{(2)}$ and the MTS, which determine that every act of RS must presuppose the existence of a medical control and any patient has the right to wait for medical care ${ }^{(8)}$.

In view of this problem and considering that some Brazilian institutions condition nurses to discharge patients after RS, exempting medical assistance, the Regional Nursing Councils, in order to resolve this ethical dilemma, issued a technical opinion that prohibits nurses from RS dismiss patients or refer them to another health unit. However, they recommend that the institution develop and adopt institutional protocols to guide this purpose $\mathrm{e}^{(38)}$. Additionally, a very accurate assessment by RS nurses is required ${ }^{(8)}$ and the establishment of clinical management rules, through the construction of clear flows previously agreed within the emergency care network ${ }^{(2,8)}$.

\section{Study limitations}

The fact that it was carried out in a single center and the use of medical records as a data source were limitations of the study, so that the incompleteness of the records must be considered, especially with regard to the vital sign variable. In this regard, it is suggested that further studies be carried out in other scenarios that use MTS from primary data.

\section{Contributions to nursing and health}

The results of this research provided important information that can assist in assessing the performance of the MTS. From the data presented, standardization strategies and improvements in care can be developed, in addition to enabling the implementation of corrective measures, considering the need to assess the measurement of vital signs to increase patient safety and prioritize patients with real urgency for care, in addition to contributing to the service organization.

\section{CONCLUSIONS}

Individuals in the white category were more advanced in age, and men had a higher percentage in the red and white category when compared to women. There is a significant relationship between the high priority categories (red and orange) with clinical severity, evidenced by the higher percentage of abnormalities of vital signs, by altered blood glucose, by the performance of two or more tests, by the higher prevalence of DM and heart diseases. The highest percentages of patients with pain records were in the yellow category, and the occurrence of external causes, in the red category. The highest percentages of patients with pain records were in the yellow category, and the occurrence of external causes, in the red category. The priority levels assigned by the MTS were also related to different outcomes. The categories of high priority red and orange were associated with higher occurrences of deaths and hospitalization, respectively. The low priority categories (green and blue) were related to higher percentages of dismissals after RS, and the white category, to higher rates of transfer to another service.

\section{FUNDING}

Coordination for the Improvement of Higher Education Personnel (CAPES - Coordenação de Aperfeiçoamento de Pessoal de Nível Superior).

\section{REFERENCES}

1. Parenti N, Reggianil ML, lannone P, Percudani D, Dowding D. A systematic review on the validity and reliability of an emergency department triage scale, the Manchester Triage System. Int J Nurs Stud 2014;51(7):1062-9. https://doi.org/10.1016/j.ijnurstu.2014.01.013.

2. Ministério da Saúde (BR). Portaria no 1.600 de 7 de julho de 2011 . Reformula a Política Nacional de Atenção às Urgências e institui a Rede de Atenção às Urgências no Sistema Único de Saúde (SUS) [Internet]. Brasília: Ministério da Saúde. 2011 [cited 2019 Dec 15]. Available from: http://bvsms.saude.gov.br/bvs/saudelegis/gm/2011/prt1600_07_07_2011.html

3. Chiu IM, Lin YR, Syue YJ, Kung CT, Wu KH, Li CJ. The influence of crowding on clinical practice in the emergency department. Am J Emerg Med. 2017;0(0):5. https://doi.org/10.1016/j.ajem.2017.07.011

4. Kawano T, Nishiyama K, Hayashi H. Execution of diagnostic testing has a stronger effect on emergency department crowding than other common factors: a cross-sectional study. PLoS One 2014;9(10):e108447. https://doi.org/10.1371 / journal.pone.0108447

5. Jo S, Jeong T, Jin YH, Lee JB, Yoon J, Parque B. ED crowding is associated with inpatient mortality among critically ill patients admitted via the ED: post hoc analysis from a retrospective study. Am J Emerg Med. 2015;33(12):1725-31. https://doi.org/10.1016 / j.ajem.2015.08.004

6. Versa GLGS, Viturib DW, Buriola AA, Oliveira CA, Matsuda LM. Assessment of user embracement with risk rating in emergency hospital services. Rev Gaúcha Enferm. 2014;35(3):21-8. https://doi.org/10.1590/1983-1447.2014.03.45475 
7. Becker JB, Lopes CBT, Pinto MF, Campanharo CRV, Barbosa DA, Batista REA. Triage at the Emergency Department: association between triage levels and patient outcome. Rev Esc Enferm USP. 2015;49(5):783-89. https://doi.org/10.1590/S0080-623420150000500011

8. Mackway-Jones K, Marsden J, Windle J, (Eds.). Emergency triage: Manchester Triage Group [Internet]. 3nd ed. Chichester (UK): John Wiley \& Sons, Ltd.; 2014 [cited 2020 Dec 05]. 192p. Available from: https://onlinelibrary.wiley.com/doi/book/10.1002/9781118299029

9. Souza CC, Arau'jo FA, Chianca TC. Scientific literature on the reliability and validity of the Manchester Triage System (MTS) Protocol: an integrative literature review. Rev Esc Enferm USP. 2015;49(1):144-51. https://doi.org/10.1590/S0080-623420150000100019

10. Martins JCA, Guedes HM, Souza CC, Chianca TCM. Association between vital signs and Manchester Triage System: a retrospective observational study. O Braz J Nurs. 2018;16(4):379-88. https://doi.org/10.17665/1676-4285.20175876

11. Santos AP, Freitas P, Martins HM. Sistema Manchester Triage versão ll e utilização de recursos no departamento de emergência. Emerg Med J. 2014; 31 2: 148-52. https://doi.org/10.1136 / emermed-2012-201782

12. Grupo Brasileiro de Classificação de Risco (BR). Diretrizes para implementação do Sistema Manchester de Classificação de Risco nos pontos de atenção às urgências e emergências [Internet]. 2017 [cited 2020 Apr 01]. Available from: http://www.gbcr.org.br/

13. Anziliero F, Soler BED, Silva BA, Tanccini T, Beghetto MG. Manchester System: time spent on risk classification and priority of care at an emergency medical service. Rev Gaúcha Enferm. 2016;37(4):e64753. https://doi.org/10.1590/1983-1447.2016.04.64753

14. Cicolo EA, Peres HHC. Electronic and manual registration of Manchester System: reliability, accuracy, and time evaluation. Rev Latino-Am Enfermagem. 2019;27: e3241. https://doi.org/10.1590/1518-8345.3170.3241

15. Mirhaghi A, Mazlom R, Heydari A, Ebrahimi M. The reliability of the Manchester Triage System (MTS): a meta-analysis. J Evid Based Med. 2017;10(2):129 - 35. https://doi.org/10.1111/ jebm.12231

16. Silva ADC, Chianca TCM, Pádua DR, Guimarães GL, Manzo BF, Correa AR. Characteristics of care of a public emergency room according to the Manchester Triage System. Rev Min Enferm. 2019;23:e-1178. https://doi.org/10.5935/1415-2762.20190026

17. Mota-Guedes HM, Araújo FA, Pinto Jr DP, Martins JCA, Chianca TCM. Outcome assessment of patients classified through the Manchester Triage System in emergency units in Brazil and Portugal. Investig Educ Enferm. 2017;35(2):174-81. https://doi.org/10.17533/udea.iee.v35n2a06

18. Oliveira GN, Vancini-Campanharo CR, Lopes MCBT, Barbosa DA, Okuno MFP, Batista REA. Correlation between classification in risk categories and clinical aspects and outcomes. Rev Latino-Am Enfermagem. 2016;24:e2842. https://doi.org/10.1590/1518-8345.1284.2842

19. Sociedade Brasileira de Cardiologia, Sociedade Brasileira de Hipertensão, Sociedade Brasileira de Nefrologia. VII Diretrizes Brasileiras de Hipertensão. Arq Bras Cardiol [Internet]. 2016[cited 2019 Oct 24];107(3supl3):1-83. Available from: http://publicacoes.cardiol.br/2014/ diretrizes/2016/05_HIPERTENSAO_ARTERIAL.pdf

20. Instituto Latino Americano de Sepse. Implementação de protocolo gerenciado de sepse: protocolo clínico [Internet]. 2018 [cited 2019 Dec 10]. Available from: https://www.ilas.org.br/assets/arquivos/ferramentas/protocolo-de-tratamento.pdf

21. Sociedade Brasileira de Cardiologia. III Diretrizes da Sociedade Brasileira de Cardiologia sobre Análise e Emissão de Laudos Eletrocardiográficos. Arq Bras Cardiol [Internet]. 2016 [cited 2019 Dec 08];107(supl 1):1-23. Available from: http://publicacoes.cardiol. br/2014/diretrizes/2016/01_III_DIRETRIZES_ELETROCARDIOGR\%C3\%81FICOS.pdf

22. Sociedade Brasileira de Diabetes. Diretrizes da Sociedade Brasileira de Diabetes: 2019-2020 [Internet]. 2019 [cited 2019 Dec 12]. Available from: https://www.diabetes.org.br/profissionais/images/DIRETRIZES-COMPLETA-2019-2020.pdf

23. Vasconcelos LB, Frota TEM. Men's Health in Primary care: experience report. Cad ESP Ceará [Internet]. 2018[cited 2019 Oct 24];12(1):116-29. Available from: http://cadernos.esp.ce.gov.br/index.php/cadernos/article/view/135

24. Mendes TJM, Silveira LM, Silva LP, Stabile, AM. Association between reception with risk classification, clinical outcome and the Mews Score. Rev Min Enferm. 2018;22:e-1077. https://doi.org/10.5935/1415-2762.20180007

25. Silva JS, Cruz TAF, Ribeiro CJN, Santos VS, Alves JAB, Ribeiro MCO. Pain in patients attended at risk classification of an emergency service. Rev Dor [Internet]. 2016 [cited 2019 Dec 12];17(1):34-8. Available from: http://www.scielo.br/pdf/rdor/v17n1/1806-0013-rdor-17-01-0034.pdf

26. Viveiros WL, Okuno MFP, Campanharo CRV, Lopes MCBT, Oliveira GN, Batista REA. Pain in emergency units: correlation with risk classification categories. Rev Latino-Am Enfermagem. 2018;26:e3070. https://doi.org/10.1590/1518-8345.2415.3070

27. Oatley M, Fry M, Mullen L. A cross-sectional study of the clinical characteristics of cancer patients presenting to one tertiary referral emergency department. Inter Emerg Nurs. 2016;24:35-8. https://doi.org/10.1016/j.ienj.2015.05.007.

28. Di Martino P, Leoli F, Cinotti F, Virga A, Gatta L, Kleefield S, Melandri R. Improving vital sign documentation at triage: an emergency department quality improvement project. J Patient Saf. 2011;7(1):26-9. https://doi.org/10.1097 / PTS.0b013e31820c9895

29. Tysinger EL. How vital are vital signs? A systematic review of vital sign compliance and accuracy in nursing. J Sci Med [Internet]. 2015 [cited 2019 Dec 12];1 (1):68-75. Available from: https://pdfs.semanticscholar.org/50cb/9aa24c1bc6f0ab59d902ab8c7411c41537f5.pdf

30. Chang $\mathrm{CY}$, Abujaber S, Pany MJ, Obermeyer Z. Are vital sign abnormalities associated with poor outcomes after emergency department discharge? Acute Med. 2019;18(2):88-95. https://doi.org/10.1097/ PTS.0b013e31820c9895

31. Gabayan GZ, Gould MK, Weiss RE, Derose SF, Chiu VY, Sarkisian CA. Emergency department vital signs and outcomes after discharge. Acad Emerg Med. 2017;24(7):846-54. https://doi.org/10.1111/acem.13194

32. Eckart A, Hauser SI, Kutz A, Haubitz S, Hausfater P, Amin D, et al. Combination of the National Early Warning Score (NEWS) and inflammatory biomarkers for early risk stratification in emergency department patients: results of a multinational, observational study. BMJ Open. 2019;9:e024636. https://doi.org/10.1136/ bmjopen-2018-024636 
33. Rocha TF, Neves JG, Viegas K. Modified early warning score: evaluation of trauma patients. Rev Bras Enferm. 2016;69(5):850-55. https://doi. org/10.1590/0034-7167-2015-0145

34. Fuller T, Fox B, Lake D, Crawford K. Improving real-time vital signs documentation. Nurs Manag. 2018;49(1):28-33. https://doi.org/10.1097 / 01.NUMA.0000527716.05512.4e

35. Koch C, Roberts K, Petruccelli C, Morgan DJ. The frequency of unnecessary testing in hospitalized patients. Am J Med. 2018;131(5):500-03. https://doi.org/10.1016/j.amjmed.2017.11.025

36. Lapić I, Juroš GF, Rako I, Rogić D. Changing the electronic request form proves to be an effective tool for optimizing laboratory test utilization in the emergency department. Int J Med Inform. 2017;102:29-34. https://doi.org/10.1016/j.jimedinf.2017.03.002

37. Marconato RS, Monteiro MI. Risk classification priorities in an emergency unit and outcomes of the service provided. Rev Latino-Am Enfermagem. 2017;25:e2974. https://doi.org/10.1590/1518-8345.2345.2974

38. Conselho Regional de Enfermagem da Bahia. Parecer Coren-BA n. 018/2016 [Internet]. 2016 [cited 2019 Dec 13]. Available from: http:// ba.corens.portalcofen.gov.br/index.php?s=PARECER+COREN-BA+018\%2F2016+\%E2\%80\%93+CT 